Social Work/Maatskaplike Werk Vol 55 No 2; Issue 1

http://socialwork.journals.ac.za/pub

doi:http://dx.doi.org/10.15270/52-2-679

\title{
FOSTERING AWARENESS OF SELF IN THE EDUCATION OF SOCIAL WORK STUDENTS BY MEANS OF CRITICAL REFLECTIVITY
}

SB Ferreira ORCID iD is 0000-0002-5220-8167

RJ Ferreira ORCID iD is 0000-0001-7047-9027

KEYWORDS: self, self-awareness, critical reflectivity, macro-conceptualisation, social work education, death and dying, African-centred world view

Prof. Sandra Berna Ferreira, Department of Social Work, University of the Free State, Bloemfontein, South Africa.

Prof. Regardt Jacobus Ferreira, Research Fellow of the Department of Social Work, University of the Free State. Director, Disaster Resilience Leadership Academy, Tulane School of Social Work, Tulane University \#8906, 127 Elk Place, New Orleans, LA 70112-2627, United States of America.

Sandra Berna Ferreira, Regardt Jacobus Ferreira

Fostering awareness of self in the education of social work students has focused primarily on a microconceptualisation of the self, which implies that the attention was, and still is, mainly on the intrapsychic processes generated by theory and field practicum. But the development of the professional self should also encompass a macro-conceptualisation, where students have to ask themselves how they contribute to the maintenance of societal structures and how these structures influence them in the forming of their own assumptions and belief systems about the self and the world. Three categories of critical-reflectivity questions can be asked about a parable on death and dying, thereby sensitising students to the self as a product of, as well as a co-creator of, society in the grieving process. These questions furthermore resonate within an African-centred worldview in the understanding of the self.

\section{FOSTERING AWARENESS OF SELF IN THE EDUCATION OF SOCIAL WORK STUDENTS BY MEANS OF CRITICAL REFLECTIVITY}

\section{Sandra Berna Ferreira, Regardt Jacobus Ferreira}

SB Ferreira ORCID iD is 0000-0002-5220-8167

RJ Ferreira ORCID iD is 0000-0001-7047-9027

Prof. Sandra Berna Ferreira, Department of Social Work, University of the Free State, Bloemfontein, South Africa.

Prof. Regardt Jacobus Ferreira, Research Fellow of the Department of Social Work, University of the Free State. Director, Disaster Resilience Leadership Academy, Tulane School of Social Work, Tulane University \#8906, 127 Elk Place, New Orleans, LA 70112-2627, United States of America.

KEYWORDS: self, self-awareness, critical reflectivity, macro-conceptualisation, social work education, death and dying, African-centred world view 


\section{INTRODUCTION}

One of the core aims of social work education is the development and consolidation of a professional identity as a social worker. In order to accomplish this, the graduate needs to master, amongst other things, an understanding of the self as an important instrument of intervention (CHE, 2015:9). Knowing the self is essential for using the self as an instrument for empowering service users. Self-knowledge starts with self-awareness, which Kondrat (1999:451) defines as a necessary condition for competent social work practice. Several tools and strategies are used to enhance the vital skill of self-awareness (Kaushik, 2017:24). In their enhanced conceptual framework on social work's signature pedagogy, Larrison and Korr (2013: 200-201) focus on, amongst other things, the development of the professional self. A modality for accomplishing this on the part of social work educators is to engage the student in the practice of critical reflectivity during the process of developing awareness of self for the professional self.

Critical reflectivity involves an appraisal of the assumptions underlying foundational ideas or beliefs about how the self and the world work. The development of awareness of the self and the capacity for critical reflectivity can contribute to ensuring understanding of the connection between the self and the social context.

The effective use of the self as an instrument in the professional relationship implies self-awareness in order to communicate and interact with service users in a way that will facilitate social change and development to their benefit and for their wellbeing (Heydt \& Sherman, 2005:26; Barnard, 2012; Kaushik, 2017:21). At first the concept of the conscious use of self as an intervention tool is new for social work students in understanding who or what the self is. The use of self, according to Dewane (2006:545), entails the combination of enabling students to integrate social work knowledge, values and skills, on the one hand, and aspects of their personal self, including personality traits, belief systems, life experiences and cultural heritage, on the other. For Kaushik (2017:23), self-awareness becomes crucial in "developing cultural competence, and also in effective "use of self". However, the self is not located only in the inner world of the identity of the individual, as often implied in Western thought, but is constantly constructed and reconstructed through the interrelations of self and social relationships and structures (Barnard, 2012:104-110). This point of departure aligns with the principle and value of the interconnectedness of all things, and with a collective identity and inclusive nature of the family structure in an African-centred worldview (Mabvurira, 2018), or the ubuntu notion of I am, because you are, that is, being a person through other people.

The purpose of this article is: i) to argue for employing critical reflectivity to develop awareness of self about the connections between personal experiences and the broader social context, and ii) to ask critical-reflectivity questions based on a parable in order to illustrate how this can be accomplished in class discussions.

Using Kondrat's (1999) alternative framework, which is based on Giddens's theory of structuration (1984), for exploring the 'self' in self-awareness, questions are posed during class discussions to finalyear Bachelor of Social Work (BSW) students about the parable of "The horse on the dining-room table". Employing critical reflectivity, students become perceptive about the self as a construct that emerges within specific societal structures. This proposed alternative framework engages the student in the conceptualisation of the self on a macro level, thereby developing an understanding of how the self is conceptualised as intimately involved in society's structures, as both an agent or creator as well as a product, in the present case, of belief systems and assumptions regarding death and dying.

\section{DEVELOPING A PROFESSIONAL SELF}

The social worker acting as the agent or instrument of intervention in the helping relationship with client systems demands a closer look at the concept of self in self-awareness. How the concept of self is constructed depends on the disciplinary tradition employed and the context in which the concept is used. Within the African context, social work educators sought to move away from 'Western' traditions 
and develop approaches to professional teaching and practice appropriate to the African postcolonial context (Gray, Kreitzer \& Mupedziswa, 2014). Baloyi and Makobe-Rabothata (2014:235) conceptualise the self or selfhood within an African worldview through envisioning the human life cycle in three phases of selfhood. There is a spiritual selfhood, which begins at conception, or even earlier in an ancestral spirit, and reincarnates; a social or experiential selfhood, which begins at conception of the cycle from a rite of incorporation or introduction of the child into the human community through to death; and an ancestral selfhood, which follows biological death. These selfhoods do not exist as autonomous, independent entities and in isolation. They are interdependent, interrelated and coexist in a collaborative and collective way; hence the concept of a collective or interdependent self (Baloyi \& Makobe-Rabothata, 2014:235) or "I am, because we are; and since we are, therefore I am" (Mbiti, 1970:141). The self is defined and understood in relation to the others, and derives its meaning from its relational connectedness to others. The Global Standards for the Education and Training of the Social Work Profession also asserts that students should have the opportunity to develop self-awareness in relation to their cultural values, beliefs, traditions and biases, and understand how these might influence their interactions with diverse populations (Akintayo, Hämäläinen \& Rissanen, 2016).

Within a macro-conceptualisation of social work, the self can be conceptualised as "an internal sense of personality integration and continuity that encompasses one's life history, accrued identification and values, and relationships with others" (Sands, 1996:169). Sodowsky, Kwan and Pannu (1995:137) state: "The identity that one constructs represents a set of internalised meanings that one attributes to the self in a social position or role. An identity, then, serves as a standard or reference for who one is." Thus: Who am I the personal? Who am I the professional? Who are we? The fundamental question is, consequently: How should the process of incorporating the personal and professional selves of the social work student be facilitated and managed in the context of social work education? This conscious use of the self as an instrument of the profession may well be a new concept for social work students (Heydt \& Sherman, 2005:26).

According to Horner (2012:13), becoming and being a social worker is "a journey of personal and professional discovery". Nearly a century ago Lee and Kenworthy (1929:215) observed that the period of education is marked also by certain definite personality developments for the social work student. This journey of personal and professional discovery for social work students entails, amongst other things, awareness of the 'self' and the 'professional self' (Bartkeviciene, 2014). Consequently, social work students' awareness of self is a prerequisite for the eventual "effective conscious use of self" (Heydt \& Sherman, 2005:27), while Copeland and Oliphant (2014:45) point out that the development of the professional self is considered by many educators as an essential component of graduate training. In order to integrate the skills required for social work practice into the authentic self, Walters (2008:8) suggests that it may be helpful to address the use of self on the basis of the belief system of the student as a construct. Questions such as: "What is the student's method of understanding, organising and making sense of the world and what are their personal views of the world?" can be helpful in order to understand the wider social and cultural factors that shape these belief systems (Hodgson \& Watts, 2017:229).

One of the essential skills for developing a professional self is to know thyself or develop an awareness of self in order to take the initial step to understanding others (Locke, 1986:1-2; Bartkeviciene, 2014:13). However, according to Lishman (2009:370), the current emphasis is often on vocational training and the achievement of discrete technical competencies in a culture that promotes market forces, consumerism and managerialism at the expense of fundamental aspects of social work. When students embark on social work training, they do not necessarily anticipate the psychological strain and the accompanying changes they will undergo in developing a professional self, or how the personal self is restructured into a professional self (Urdang, 2010: 523-524). These emotional demands need to be foreseen, acknowledged and addressed in the classroom and during supervision in order to prevent possible harm to the professional and personal development of the student (Yip, 2006:787). For this 
reason Copeland and Oliphant (2014:46) maintain that teaching students self-awareness by means of different assignments has to focus on helping them "[assess, analyse and comprehend] how their life experiences, values and beliefs influence how they perceive the world and others around them".

Awareness of self in practice situations is an essential principle and a necessary condition for competent social work practice (Kondrat, 1999:451). Both Dominelli (2009:55) and Payne (2014:22) confirm that getting to know the self is crucial to working in personal and socially empowering ways with others who are different. Exploring and developing a professional identity where the self is understood as being interconnected with, and constructed within, specific social contexts therefore needs to be an aim of social work education. Critical reflectivity as construct has been posited by Kondrat (1999) as a means by which the social work student can explore the question of who the self is in professional self-awareness.

\section{SELF-AWARENESS}

Although the profession has been consistent in advocating the importance of developing awareness of self or self-awareness, social work literature varies a great deal in the way the topic is understood (Dettlaff, Moore \& Dietz, 2006:88; Kondrat, 1999:452; Lishman 2009:375-377; Payne, 2014:89-91). Self-awareness begins with reflection (Yip 2006:780; Bartkeviciene, 2014:12), where one becomes the subject of one's own attention (Legrain, Cleeremans \& Destrebecqz, 2010:578; Morin, 2011:807). Other relevant and related concepts used in literature to conceptualise this endeavour of becoming aware of self are reflective practice, reflexivity and critical reflection, but these are often conflated or used indiscriminatingly without clear definition and uniformity (Askeland \& Fook, 2009:289; Hickson, 2011:831; Marlowe, Appleton, Chinnery. \& Van Stratum, 2014:62).

Becoming self-aware is a process that continues throughout the lifespan of the social worker. During the period of training to become a social worker, the process starts with the heightening of selfawareness and with the ability to look at and recognise oneself - sometimes as judgemental, prejudiced and non-caring. Self-awareness is the ability to recognise when the judgemental, non-caring self interfaces with the ability to reach out, to explore and to help others mobilise their coping capacities (Harris, 1997:591). Devore and Schlesinger (1996:115) emphasise how self-awareness can influence professional practice; they maintain that self-awareness encompasses the capacity to recognise that shortcomings and strengths may trigger our tendencies for empathy or destructiveness. According to Meek (2005:37), this necessitates that training programmes take additional responsibility for promoting self-awareness, where, according to Baldwin (1999:xxii), respect for the self, the 'other' and the context is fostered.

Developing self-awareness in order to give momentum to the process of professional socialisation in building professional identity should consequently be emphasised in social work education. Fostering self-awareness is a starting point for becoming a reflective practitioner. Conventionally, three traditional approaches to professional self-awareness are implemented in social work literature and are used in social work education (Kondrat, 1999:452). These approaches correspond to an implicit conceptualisation of 'self', that is, a 'sense of personal identity', as well as to the assumptions about 'the sort of person one is.'

Simple conscious awareness (awareness of whatever is being experienced) is unselfconscious in the sense that attention and awareness are directed to what is experienced by the self rather than to the self who is experiencing. The self is merely understood as the perceiving subject, as the locus for sensations, perceptions, and impressions. The self is aware of, and can recognise, what it is experiencing. It is about the 'here-and-now' contact with the environment or the implicit self or 'I' (Legrain et al., 2011:578). The literature on training for basic skills offers suggestions to students on how to attend to the practice situation, with particular emphasis on developing accurate listening and observation behaviours. Later, the student is required to recall and produce in writing the exact details 
of the encounter by means of a process report (Kondrat, 1999:452-453), for example, hearing, observing and remembering what and how the client has communicated.

Reflective self-awareness (awareness of a self who is experiencing something) is self-knowledge. The student becomes 'objective' about the self by distancing the subjective element as far as possible. The self's behaviour, affect and cognitions become the objects of reflection. This kind of reflection objectifies the experience by distancing the knower from that which is known, that is, the 'I' is capable of standing apart and evaluating behaviour, cognition, affect and behaviours of the 'me' - for example, students are expected to share their opinions about working with a sex offender (Kondrat, 1999:454455). Recommendations for the conscious use of the self, or for increasing objectivity, are engaging in good supervision, and using tools such as journals, and audio and video tapes.

Reflexive self-awareness (the self's awareness of how his/her awareness is constituted in direct experience) does not simply entail descriptive statements about an objective self, "but expressions of that self" (Kondrat, 1999:456). The distance and otherness are reduced, as the 'I' and 'me' occupy the same 'space'. Reflexive self-awareness forms the basis for key conceptual functions such as personal meaning, interpersonal and interpretive understanding, and empathy as a way of knowing the self and others. The self-construct is defined partly in dialogue with other people's understanding of who the self is, that is, it is co-constructed in interaction with the social and physical environment, and mediated through language and culture (Kondrat, 1999:457-458) - for example, where the student has been a victim of rape and how the client's narrative about rape influences the social work student.

However, according to Kondrat (1999:460-464), the above points can be seen as focusing on the individual psychology of the student in the development of self-awareness or 'psychologisation', also called a micro-conceptualisation of self-awareness. Moving from this to an understanding of the self from a sociological perspective, or a structural explanation, should be included in the way social work educators help the student in the process of developing self-awareness.

\section{CRITICAL-REFLECTIVITY SELF-AWARENESS}

Using Giddens's (1984) structuration theory, Kondrat (1999:460-470) outlines a macroconceptualisation of the self, derived from critical theory, namely critical reflectivity. One of the main points of departure of critical theory is that social problems are created more by the structure of society and the cultural assumptions generated by dominant groups that oppress subordinate groups. As a theoretical framework for social work, it has been enriched by an analysis of the complex processes of colonialism, decolonisation and de-colonialism (Long, 2005; Campbell \& Baikie, 2012), while at grassroots level it helps "social workers to avoid assuming that the way things are, is the way they have to be" (Payne, 2014:319). The emergence of critical social work theories and anti-oppression approaches over the past few years has brought about an expanded conceptualisation of the 'self' of the social worker. The understanding of the use of the self is focused on identifying and decisively reducing power imbalances. To address this level of awareness of the professional self requires "that [one's] own perspectives must be interpreted in the light of changing and specific situations in which they are located" (Fook, 2016:99-100).

Giddens's structuration theory offers an approach to self-awareness that incorporates macro considerations as a necessary part of the definition of what it means to be a self-aware, reflective practitioner (Kondrat, 1999:470). Ferguson (2013:28) argues that Giddens placed the capacities of human beings to reflect on their lives and adjust their actions accordingly - what Giddens called reflexive monitoring of conduct - at the core of his structuration theory. In the 1990s Giddens developed his theory of reflexive modernisation and the reflexive project of the self. According to his theory, there is a recursive quality to the relation between human beings and their social structures and institutions. Society and its structures are both condition and outcome of the actions of human beings in time; persons, as selves and as identities, are shaped, sustained and modified by structures and practices of their socialising communities and societies. Therefore, social workers can reproduce social 
structures through unreflective practice. Social structures that are not beneficial for client systems, or rules and resources that are disabling conditions, do not allow social transformation to take place.

Fook (2016:56-57) states that, in developing a critical reflective practice, practitioners must be able to value and apply a process of reflecting on practice from a stance of reflexivity, where 'reflexivity' comprises being able to question "the ways in which their own backgrounds, embodiment, personalities, and perspectives intermingle" and influence their thinking and their actions as practitioners. Critical reflection takes place when the social work student is able to understand and challenge the validity of their assumptions. Students not only have to understand their assumptions and their beliefs within the social context, but grasp how these can influence their approach to intervention (Hickson, 2011:831). By means of critical reflectivity, they are enabled to question how their experiences in life are influenced by, and interact with, many different worlds. This is what Kondrat (1999:469) describes as more than "a simple reflection on personal beliefs, intentions, affects and attitudes", as the focus is on how the students" "own backgrounds, embodiment, personalities, and perspectives intermingle in a holistic context" (Fook, 2016:56).

Fook and Gardner (2007:14) regard individuals as social beings whose personal characteristics are formed and reformed in interaction with, and within, different facets and levels of their social worlds. Self-awareness from a critical-reflectivity standpoint therefore enables social work students in their journey to be mindful of, sensitive to, and cognisant of the broader influence on how the 'self' is formed within a broader context of living, and how that can impact on their interaction with people.

\section{THREE TYPES OF QUESTIONS USING CRITICAL REFLECTIVITY}

The point at issue now is: What are the implications of this way of understanding the conceptualisation of what it means to be a self-aware, reflective practitioner, or on what 'content' is the self supposed to reflect? According to Fook (2016:102), a significant implication of this complex view of self is that there are many aspects of the self which are formed in a social context. She points out that there are at least three key structural categorisations which are commonly used to define people socially, namely race, class and gender. She adds other dimensions to these categories, aspects such as ethnicity, age, ablement (dis/ability), health and sexuality. Using three types of questions as formulated by Kondrat (1999:465), students have to take into account the above elements when reflecting critically on their assumptions and perspectives, and how these might contribute to discrimination and oppression within the context of death and dying, and the self as creator and product of these features. These questions can be seen as part of what Fook $(2016: 117,120)$ refers to as the "unsettling of dominant discourses" or "the deconstruction step of the critical reconstructive process, the first step in questioning dominant discourses". Looking for contradictions in, as well as different perspectives on and interpretations of, the dominant discourse about dying and death (the individual in social context) is needed to bring into the open the student's perspective on power relations and structures (Fook, 2015:121). The strength or power of dominant discourses is located in the fact that they are unquestioned. By means of critical reflectivity, students question their assumptions or perspectives on personal discourses and the source of these perspectives, thereby unearthing how they themselves participate in the discourses that shape existing power relations (Fook, 2016:127).

\section{CRITICAL REFLECTIVITY IN THE MODULE ON LOSS AND TRAUMA BY MEANS OF A PARABLE: "THE HORSE ON THE DINING-ROOM TABLE"}

At the beginning of their final year, social work students at a South African university receive a 12credit module or 120 notional hours of teaching and learning on loss and trauma. The class is multiracial and representative of the socio-demographic profile of the broader community. Teaching experience in this field has indicated that being challenged with grief- and trauma-related information and being asked to reflect on their own situations of loss and trauma, requires and leads to active engagement with the personal and professional self on the part of students. An oral agreement is concluded during the first class session, at which students are encouraged to report for individual 
supervision and/or can request a referral for personal therapeutic psychological sessions on account of the content of the module. Furthermore, ground rules pertaining to confidentiality, as well as for the execution and presentation of assignments, are clarified. The content of the module and the working method, specifically the class discussions (i.e. the parable they need to reflect on as well as the way they have to reflect), are discussed. During the orientation class the students are sensitised to the following features: how their assumptions and beliefs are shaped by experiences, interactions and responses from their social and structural context; how these social and structurally induced assumptions and beliefs influence how they interpret and behave towards others and, in their case, their client systems; and how this influences the awareness of self. The importance of a respectful, tolerant and empathic environment is stressed and observed during class discussions. This atmosphere is significant because, within African cultures, understanding and sensitivity have to be demonstrated when the constructs of death and dying are deliberated. According to Ekore and Lanre-Abass (2016:371), African people in general do not like facing the reality of death and often avoid contemplation of their own death or the death of loved ones.

The class discussions focus on the parable of "The horse on the dining-room table" by Kalish (1985). The application of the story during class discussions is utilised in the module on loss and trauma as a vehicle to cultivate awareness of self. Using critical reflectivity, students need to analyse their thoughts, feelings and actions regarding their culture's norms on death and dying vis-à-vis race, class and gender as a social structure. In this way they embrace an awareness of what Fook (2006:4) calls "how assumptions about the connection between oneself and social context/structure can function in powerful ways to maintain existing (often unequal) power relations, so that awareness of these assumptions can provide a platform for transformative action towards a more equitable society". This practical knowledge is therefore, embedded in social practices (Kondrat, 1999:462) and in this case customs and norms pertaining to death and dying.

The parable thus becomes a metaphor of how race, class and gender within culture can influence interaction, and thus the helping relationship, with grieving and traumatised individuals and families. By engaging with that, students are enabled to conceptualise the self as intricately submerged "in society's structures both as agent and as a product" (Kondrat, 1999:464) regarding beliefs, assumptions and customs in times of the death of a loved one. Individuals replicate society in their everyday activities, that is, each individual from his or her own position and set of interests acts in such a way that the structure of society is reproduced. Individuals are therefore both creations and creators of the world and their social world, or, as Kondrat (1999:471) articulates it: "We have met society and it is us." The individual is therefore not simply the passive object of society's forces or only passive inheritor of society's directives, but rather intrinsically implicated in society by acting, conforming, resisting, challenging and transforming. The individual comes to be both the product and the agent of self-transformation and social transformation.

In essence, this parable is about the narrator looking for answers to the question of what it means to die. After struggling up the slope of 'Mount Evmandu', he meets an ancient sage: "Father, I need to understand something about what it means to die before I can continue my studies. I want to know what a dying person feels when no one will speak with him, nor be open enough to permit him to speak, about his dying."

After some time, the answer is given plainly and simply: "It's the horse on the dining-room table." Many years later, the narrator is invited to dinner at the home of a casual friend. On entering the dining room together with the other guests, he sees that "a brown horse was sitting quietly on the dining-room table". All the guests, including the narrator, "gasped or stared, but said nothing". Although everyone was uncomfortable and making small talk, no one mentioned the horse on the dining-room table. The narrator left never wanting to see his hosts again. Soon afterwards, he visited the sage once more and, once again, asked him, "Father, I want to know what a dying person feels when no one will speak with him, nor be open enough to permit him to speak, about his dying?" The sage looked at him and said: 
"My son, it is the horse on the dining-room table. It is a horse that visits every house and sits on every dining-room table - the table of the rich and of the poor, of the simple and of the wise. This horse just sits there, but its presence makes you wish to leave without speaking of it. If you leave, you will always fear the presence of the horse. When it sits on your table, you will wish to speak of it, but you may not be able to.

However, if you speak about the horse, then you will find that others can also speak about the horse - most others, at least if you are gentle and kind as you speak. The horse will remain on the dining-room table, but you will not be so distraught. You will enjoy your repast, and you will enjoy the company of the host and hostess. Or, if it is your table, you will enjoy the presence of your guests. You cannot make magic to have the horse disappear, but you can speak of the horse and thereby render it less powerful."

By means of three categories of reflective questions related to this parable, students are not only encouraged to unlock alternative ways of understanding, but also to become aware of how they as future social workers can unwittingly contribute to, and reproduce, the structure of society regarding assumptions and beliefs about, amongst other things, death in their culture. These new ways of understanding may enable social work students to become aware of how social structures affect them, their clients and social work practice. This process can empower students to develop not only an understanding of how they reproduce society in what Kondrat (1999:462) terms "their everyday activities", but also to recognise, according to Fook (2016:113), that their "identities are made and understood in context and therefore may change, be contradictory and be multiple." In other words, they start to realise that their selves are constructed in relation to, and in interaction with, their social world, and, in this particular case, their social work regarding death and dying. Table 1 is a version of examples of critical-reflectivity questions put to students based on the parable.

\section{TABLE 1}

\section{EXAMPLES OF CRITICAL-REFLECTIVITY QUESTIONS TO STUDENTS}

\begin{tabular}{|c|c|c|}
\hline \multicolumn{3}{|c|}{ The world: Reflecting on different perspectives regarding death and dying in their community } \\
\hline Critical-reflectivity questions & $\begin{array}{l}\text { The horse on the dining-room } \\
\text { table }\end{array}$ & $\begin{array}{l}\text { Critical-reflectivity questions to } \\
\text { students }\end{array}$ \\
\hline $\begin{array}{l}\text { What are the structures of your } \\
\text { community/group - specifically, structures } \\
\text { related to dying? } \\
* \text { In what ways do my assumptions and } \\
\text { activities contribute to the maintenance or } \\
\text { transformation of such social structures } \\
\text { regarding dying? } \\
\text { * What do I know about how people in my } \\
\text { community are supposed to act with regard } \\
\text { to others in the same location (location in } \\
\text { relation to the social categories such as } \\
\text { class, race and gender) when it comes to } \\
\text { dying? }\end{array}$ & $\begin{array}{l}\text { * "All characters except for the sage } \\
\text { kept quiet and pretended that } \\
\text { everything was okay." } \\
\text { * "They went through [the] motions, } \\
\text { eating, chatting ..." } \\
\text { * "The narrator wanted to say } \\
\text { something, but he followed their [the } \\
\text { guests, host and hostess's] example." }\end{array}$ & $\begin{array}{l}\text { The culture I was born in: } \\
\text { * What are the main belief systems, } \\
\text { customs and practices of the culture } \\
\text { and other cultures in society, } \\
\text { concerning dying? } \\
\text { - Grieving } \\
\text { * Mourning } \\
\text { the roles of males and females during } \\
\text { times of dying in your community? }\end{array}$ \\
\hline
\end{tabular}

My world: Reflecting on what the student knows and understands about death and dying

\begin{tabular}{|c|c|c|}
\hline Critic & $\begin{array}{l}\text { The horse on the dining-room } \\
\text { table }\end{array}$ & \\
\hline $\begin{array}{l}* \text { What do I believe about my place in the } \\
\text { world? } \\
* \text { What is my understanding of how to act in } \\
\text { relation to someone belonging to a different } \\
\text { race, gender, status, and so forth? } \\
\text { * From what sources, have I learned these } \\
\text { social lessons? } \\
* \text { In what way are my beliefs about the } \\
\text { person, family or community a reflection of }\end{array}$ & $\begin{array}{l}\text { * "The narrator keeps on asking } \\
\text { questions about how he should } \\
\text { respond." } \\
\text { * "He feels uncomfortable." } \\
\text { * "He keeps on wondering about } \\
\text { the horse on the dining-room } \\
\text { table." } \\
\text { * "[In] the beginning, he did like } \\
\text { the rest ... he did not speak, did not }\end{array}$ & $\begin{array}{l}\text { * Who are you? } \\
\text { * I identify myself as .....? } \\
\text { * My way of dealing with dying is the } \\
\text { following ... } \\
* \text { I believe my role in times of death and } \\
\text { dying is the following ... } \\
\text { * Am I able and willing to ask questions } \\
\text { about dying? } \\
* \text { Do I question my and my culture's }\end{array}$ \\
\hline
\end{tabular}


other systems like ideology, religion or question his own behaviour or the belief systems, customs and practices culture? actions of the others."

* To what extent am I willing to raise * "He was open ... looking for ...? questions about social structures related to answers."

power and privilege regarding the reported issue?

*Where and how can I raise them?

Similarities and differences between the world and my world in the student community regarding death and dying. These are questions that relate to similarities and differences between what the self understands by 'my world' (society and self) and 'the world' (the lived objective circumstances of social life) (Kondrat, 1999:466).

The horse on the dining-room table

* "The narrator's actions are like [those of] the rest of the characters."

* "He speaks like the others ... he is extremely cautious."

* "He gets information from the sage."

* "He was respectful to the others during the dinner."

* "He took the initiative to get more information after questioning himself."

\section{Critical-reflectivity questions to students}

* To what extent do I accept uncritically the values, beliefs, assumptions, and prescriptions about dying, I have received because of my socialisation into particular communities?

* Are there inconsistencies or distortions between my received beliefs/assumptions and the concrete conditions of individual and group life regarding dying?

* Choose one character in the parable and indicate how you would have behaved in the situation. What would your actions be and on what would you base them?

In reflecting on these questions, students have the chance not only to analyse and identify their construction of power regarding race, class and gender within a situation as depicted by the parable of "The horse on the dining-room table", but also to question their own and dominant constructions on death and dying in their communities, and labelling these as such. By looking at the differences and similarities between 'the world' and 'my world', they are enabled to deconstruct, exchange and change existing constructions, and create new perspectives during class discussions.

Critical-reflective contemplation fosters the realisation for students that they are "social actors of their subjective understandings of society and self" and that neither social conditions nor intersubjective meanings alone are able to embrace all of reality (Kondrat, 1999:466). They are both an actor and product of society's structures. Self-reflection, therefore, is "always a reflection on society and vice versa" (Kondrat, 1999:465), or, as Fook (2006:2) suggests, "understanding the individual in social context". It is about: who the student is as a person; the social position the student occupies; the specific historical time or macro-context the student lives in at present; and the micro-context (e.g. the classroom the student is in). This refers to what Fook (2016:57) conceptualises as the interconnectedness between the ability to reflect and be reflexive, and the ability to identify and analyse the influence of the context.

\section{DISCUSSION}

The intention of this article is to argue, by way of a parable, for the practice of employing critical reflectivity to develop awareness of self regarding the connections between personal experiences and the broader social context. The literature indicates that the origins of the social work profession continuously emphasised the social side of human existence. The awareness of the social environment and its influence on the lives of individuals was the primary starting point when social problems had to be addressed, while the construct of the person-in-environment gave direction to social work interventions. However, the quest for acceptance as a profession created the "need to scientise" social work knowledge within an individual and intrapsychic explanation of human behaviour and personal problems (Fook, 2016:4-5). Dating back as far as the early 1990s, there have been accusations that the profession has lost track of its traditional mission of promoting social health, social justice and social cohesion (Specht \& Courtney, 1994) and that the focus is more on an intrapsychic explanation for behaviour and personal problems. This might have been the case in some Western countries, especially 
the USA, because both Fook (1993) and Healy (2001) indicate the emergence of a radical critique in the 1960s that led to a refocus on the issue of the social context. The IFSW also addressed the matter of promoting social justice and social cohesion in the 2014 global definition of social work. The call for the implementation of the African-centred worldview in social work, often referred to as 'decolonisation', underline the necessity for revisiting the self in self-awareness in the South African context. Critical reflectivity helps the social work student by means of self-awareness to question how the self can constitute and maintain the environment, structures or society, that is, self as both cocreator and product. Nonetheless, the micro-conceptualisation of the self is still valid, but it needs to be integrated with the self as it emerges within specific social contexts - that is the self as a co-constructor and product of the individual's direct settings.

In the absence of critical reflectivity, students fail to question, and they consequently uphold and reproduce social structures and modes of oppression, even when thinking that they have the best intentions of helping people. Students have to be enabled to ask themselves how social structures can affect social work practice, thereby reflecting on whether they themselves, and eventually social work practice, are sustaining oppression and injustice. Awareness of self, using critical reflectivity, can make social work students aware that they and social work practice could in fact become instruments of oppression and injustice that can increase social exclusion, poverty and marginalisation of the very people they want to help. Even in a module on loss and trauma, class discussions using critical reflectivity can challenge students to explore and understand to what extent they are aware of the manner in which societal structures and arrangements condition their awareness and action. They become aware of the manner in which everyday activities over time constitute and reconstitute a society fraught with oppression, injustice, social exclusion and marginalisation (Kondrat, 1999:461).

The professional self requires an awareness of self, or what Baretti (2004:257) terms the "importance of developing self-awareness". The emphasis in the professional socialisation of students during social work education seemed to have been on simple conscious awareness, reflective awareness, understanding how the person of the practitioner influences clinical performance, and becoming aware of those processes through which the self interacts with others to create significance and identities. However, using critical reflectivity in teaching and learning about a sensitive topic such as dying can enhance awareness of the self by helping the student to understand and challenge the validity of their own assumptions as influenced by the context of social assumptions. Awareness of self entails an intersection of individual identity and social identity.

Reflective questions about the self should therefore not be confined to micro-examination of personal understandings, affects and motivations, as many social work students will identify no personal prejudices and might even be able to distance themselves from racism, ageism and other 'isms'. If critical reflectivity as an approach to self-awareness is used, the starting point is the assumption that no one and no institution escapes complicity in society and its structures (Kondrat, 1999:468). Questions like the following are asked: "What have I learned about how to perceive, or how to relate to, members of my own or other groups (gender, race, class), and what is the source of that learning? What do I as a middle-class, ethnic/cultural, professional, male/female know about how to relate to and interpret the behaviour of others who occupy similar as well as different social locations? What have I learned about how to interpret the behaviour of someone whose self-identification is based on my specific race and cultural group?" Critical reflectivity empowers the student to understand and explore the notion that through their actions they uphold certain structures, the very same structures they often question or should question.

Critical reflectivity is not a simple reflection on personal dogmas, intentions, affects and attitudes (Kondrat, 1999:469), but about developing awareness of self within the context of structures or situational contexts of power, marginalisation, exclusion and oppression embedded within culture. Critical self-awareness includes macro-reflections as a definition of what it means to be a self-aware, reflective practitioner. When students are able to practise critical self-awareness, they are able to respect and value differences in their client systems. The initial step to understanding others is therefore 
critical self-awareness, as it increases sensitivity to client systems from different cultural, racial and ethnic milieus. It helps social work students to make sense of, and talk about, social work practice.

Becoming aware of the self as a component of graduate training can be cultivated and fostered by means of critical reflectivity from the vantage point of a macro-conceptualisation of social work, even in a module on loss and trauma using a parable such as "The horse on the dining-room table".

\section{CONCLUSION}

Developing self-awareness is a fundamental process in the professional development of the social work student. Through using critical-reflectivity questions, a process is fostered in the student to understand that awareness of self is constructed by way of an interaction between personal and societal structures. Self-awareness helps students to understand that they are both a product and creator of social structures, sometimes unwittingly not only in terms of the self, but for service users as well.

Attending to a macro-conceptualisation of the self, social work students' cultural competence in working with client systems from different cultural backgrounds is addressed and developed. Combining the parable of "The horse on the dining-room table" and critical reflectivity can be unsettling and uncomfortable for social work students at first, as it implies that they have to scrutinise, question, and sometimes adjust and change their assumptions and beliefs about the self and the other. However, this process of deconstruction of assumptions and beliefs should take place within a structured academic environment, thereby creating a sense of safety for the student in the conceptualisation of the self on a macro-level as part of developing the professional self.

\section{REFERENCES}

AKINTAYO, T., HÄMÄLÄINEN, J. \& RISSANEN, S. 2016. Global standards and the realities of multiculturalism in social work curricula. International Social Work, 61(3):395-409.

ASKELAND, G.A. \& FOOK, J. 2009. Critical reflection in social work. European Journal of Social Work, 12(3):287-292.

BALDWIN, M. 1999. Use of self in therapy. ( $2^{\text {nd }}$ ed). New York, NY: Haworth.

BALOYI, L. \& MAKOBE-RABOTHATA, M. 2014. The African conception of death: A cultural implication. In: JACKSON, L., MEIRING, D., VAN DE VIJVER, F. \& INDEMUDIA, E. (eds). Toward sustainable development through nurturing diversity. Selected papers from the Twenty First International Congress of the International Association for Cross-Cultural Psychology. Stellenbosch, South Africa: International Association for Cross-Cultural Psychology.

BARETTI, M. 2004. What do we know about the professional socialization of our students? Journal of Social Work Education, 40(2):255-283.

BARNARD, A. 2012. The self in social work. Social Work and Social Sciences Review, 15(3):101118.

BARTKEVICIENE, A. 2014. Social work students' experiences in 'self' and professional 'self' awareness by using the art therapy method. European Scientific Journal, 10(5):12-23.

CAMPBELL, C. \& BAIKIE, G. 2012. Beginning at the beginning: an exploration of critical social work. Critical Social Work, 13(1):67-81.

COUNCIL ON HIGHER EDUCATION (CHE). 2015. Higher Education Qualifications SubFramework. Qualification Standard for Bachelor of Social Work. Pretoria, South Africa: CHE.

COPELAND, S. \& OLIPHANT, E. 2014. BSW students' personal reflection and self-correction: teaching implications. International Journal of Business, Humanities and Technology, 4(3):45-53.

DETTLAFF, A.J., MOORE, L.S. \& DIETZ, T.J. 2006. Personality type preferences of social work students. The Journal of Baccalaureate Social Work, 11(2):88-101. 
DEVORE, W. \& SCHLESINGER, E.G. 1996. Ethnic-sensitive social work practice. Needham Heights, MA: Allyn \& Bacon.

DEWANE, C.J. 2006. Use of self: a premier revisited. Clinical Social Work Journal, 34(4):543-558.

DOMINELLI, L. 2009. Anti-oppressive practice: the challenges of the twenty-first century. In: ADAMS, R., DOMINELLI, L. \& PAYNE, M. (eds) Social work: themes, issues and critical debates. 3rd ed. New York, NY: Palgrave Macmillan.

EKORE, R.I. \& LANRE-ABASS, B. 2016. African cultural concept of death and the idea of advance care directives. Indian Journal of Palliative Care, 22(4):369-372.

FERGUSON, H. 2013. Anthony Giddens. In: GRAY, M. \& WEBB, S.A. (eds). Social work theories and methods. $\left(2^{\text {nd }}\right.$ ed). Thousand Oaks, CA: Sage Publications.

FOOK, J. 1993. Radical casework: A theory of practice. St Leonards, New South Wales: Allen \& Unwin.

FOOK, J. 2006. Beyond reflective practice: reworking the 'critical' in critical reflection. Keynote for: Professional lifelong learning: Beyond reflective practice. 36th Annual SCUTREA Conference 2006. Inter-cultural perspectives on research into adult learning: a global dialogue. Leeds, United Kingdom: University of Leeds.

FOOK, J. 2015. Reflective practice and critical reflection. In: LISHMAN, J. (ed). Handbook for practice learning in social work and social care: Knowledge and theory. $\left(3^{\text {rd }}\right.$ ed $)$. London, United Kingdom: Jessica Kingsley.

FOOK, J. 2016. Social work: a critical approach to practice. Thousand Oaks, CA: Sage Publications.

FOOK, J. \& GARDNER, F. 2007. Practising critical reflection: A resource handbook. Berkshire, United Kingdom: McGraw Hill, Open University Press.

GIDDENS, A. 1984. The constitution of society: Outline of the theory of structuration. Berkeley, CA: University of California Press.

GRAY, M., KREITZER, L. \& MUPEDZISWA, R. 2014. The enduring relevance of indigenisation in African social work: a critical reflection on ASWEA's legacy. Ethics and Social Welfare, 8(2):101116.

HARRIS, M.S. 1997. Developing self-awareness/racial identity with graduate social work students. Smith College Studies in Social Work, 67(3):587-607.

HEALY, K. 2000. Social work practices: contemporary perspectives on change. Thousand Oaks, CA: Sage Publications.

HEYDT, M.J. \& SHERMAN, N.E. 2005. Conscious use of self: tuning the instrument of social work practice with cultural competence. The Journal of Baccalaureate Social Work, 10(2):25-40.

HICKSON, H. 2011. Critical reflection: reflecting on learning to be reflective. Reflective Practice, 12(6):829-839.

HODGSON, D. \& WATTS, L. 2017. Key concepts and theory in social work. London, United Kingdom: Palgrave Macmillan.

HORNER, N. 2012. What is social work? Context and perspectives. (4th ed). London, United Kingdom: Sage Publications.

KALISH, R.A. 1985. Death, grief, and caring relationships. ( $2^{\text {nd }}$ ed). Monterey, CA: Brooks/Cole.

KAUSHIK, A. 2017. Use of self in social work: rhetoric or reality. Journal of Social Work Values and Ethics, 14(1):21-29. 
KONDRAT, M.E. 1999. Who is the 'self' in self-aware: professional self-awareness from a critical theory perspective. Social Service Review, 12(4):451-477.

LARRISON, T.E. \& KORR, W.S. 2013. Does social work have a signature pedagogy? Journal of Social Work Education, 49(2): 194-206.

LEE, P. \& KENWORTHY, M. 1929. Mental hygiene and social work. New York, NY: Commonwealth Fund.

LEGRAIN, L., CLEEREMANS, A. \& DESTREBECQZ, A. 2011. Distinguishing three levels in explicit self-awareness. Consciousness and Cognition, 20 (2011):578-585.

LISHMAN, J. 2009. Personal and professional development. In: ADAMS, R., DOMINELLI, L. \& PAYNE, M. (eds). Social work - themes, issues, and critical debates. $\left(3^{\text {rd }}\right.$ ed). New York, NY: Palgrave Macmillan.

LOCKE, D.C. 1986. Increasing multicultural understanding. Newbury Park, CA: Sage Publications.

LONG, S.K.W. 2005. 'Decolonialism' and the counselling profession: the Aotearoa/New Zealand experience. International Journal for the Advancement of Counselling, 4(4):557-572).

MABVURIRA, V. 2018. Making sense of African thought in social work practice in Zimbabwe: towards professional decolonisation. International Social Work, 31 August 2018. [Online] Available: https://journals.sagepub.com/doi/full/10.1177/0020872818797997 [Accessed: 03/09/2018].

MARLOWE, J.M., APPLETON, C., CHINNERY, S. \& VAN STRATUM, S. 2015. The integration of personal and professional selves: developing students' critical awareness in social work practice. Social Work Education: The International Journal, 34(1):60-73.

MBITI, J. 1970. African religions and philosophy. Garden City, NY: Anchor Books.

MEEK, H.W. 2005. Promoting self-awareness: infant observation training as a model. Smith College Studies in Social Work, 75(3):33-58.

MORIN, A. 2011. Self-awareness. Part I. Definitions, measures, effects, functions, and antecedents. Social and Personality Psychology Compass, 5(10):807-823.

PAYNE, M. 2014. Modern social work theory. $\left(4^{\text {th }}\right.$ ed). New York, NY: Palgrave MacMillan.

SANDS, R. 1996. The elusiveness of identity in social work practice with women. Clinical Social Work, 24(2):167-186.

SODOWSKY, G.R., KWAN, K-L.K. \& PANNU, R. 1995. Ethnic identity of Asians in the United States. In: PONTEROTTO, J.G., CASAS, J.M., SUZUKI, L.A. \& ALEXANDER, C.M. (eds). Handbook of multicultural counselling. Thousand Oaks, CA: Sage Publications.

SPECHT, H. \& COURTNEY, M. 1994. Unfaithful angels: how social work has abandoned its mission. New York, NY: Free Press.

URDANG, E. 2010. Awareness of self - a critical tool. Social Work Education, 29(5):523-538.

WALTERS, H.B. 2008. Field placement: an introduction to the 'use of self' in field placement. The New Social Worker: The Social Work Careers Magazine, 15(4):8-11.

YIP, K-S. 2006. Self-reflection in reflective practice: a note of caution. British Journal of Social Work, 36(5):777-788. 